\title{
MÁS ALLÁ DEL ATEÍSMO, LA RELIGIÓN Y EL NIHILISMO. LA "IRRELIGIÓN" FILOSÓFICA DE QUENTIN MEILLASSOUX
}

\author{
Mario Teodoro Ramírez Cobián* \\ doi: 10.11144/Javeriana.uph37-75.ifqm
}

\section{RESUMEN}

En el artículo se explica y se aboga a favor de la propuesta de Quentin Meillassoux de "filosofía irreligiosa" o "irreligión filosófica", es decir, de una tercera postura entre religión y ateísmo que plantea la concepción de un Dios inexistente y por venir (Dios virtual) y de una recuperación ético-filosófica de las nociones de esperanza, iortalidad, justicia y divinidad. Con referencias a distintos pensadores de la historia de la filosofía se busca enmarcar el significado y valor de la concepción de Meillassoux. Después de una exposición breve de la filosofía del pensador francés, se realiza en sucesivos apartados la recuperación crítico-filosófica de conceptos religiosos básicos para concluir con una breve exposición de la refutación del "nihilismo" que hace Meillassoux, tarea filosófica importante como ninguna en nuestro tiempo.

Palabras clave: religión; ateísmo; esperanza; contingencia; justicia; inmortalidad

Universidad Michoacana de San Nicolás de Hidalgo, Morelia, México.

Correo electrónico: marioteo56@yahoo.com.mx

Para citar este artículo: Ramírez Cobián, M. T. (2019). Más allá del ateísmo, la religión y el nihilismo. La "irreligión” filosófica de Quentin Meillassoux. Universitas Philosophica, 37(75), 237-265. ISSN 0120-5323, ISSN en línea 2346-2426. doi: 10.11144/Javeriana.uph37-75.ifqm 


\title{
BEYOND ATHEISM, RELIGION AND NIHILISM. QUENTIN MEILLASSOUX'S PROPOSAL OF A PHILOSPHICAL "IRRELIGION"
}

\begin{abstract}
The article explains and advocates in favor of Quentin Meillassoux's proposal of "irreligious philosophy" or "philosophical irreligion", that is, of a third position between religion and atheism that defends the conception of a nonexistent God and a God to come (virtual God), as well as an ethicalphilosophical recovery of the notions of hope, immortality, justice, and divinity. With references to different thinkers in the history of philosophy, we seek to frame the meaning and value of Meillassoux's conception. After a brief exposition of his philosophy, the critical-philosophical recovery of basic religious concepts is carried out in successive sections, to conclude with a brief exposition of Meillassoux's refutation of "nihilism", an important philosophical task like none in our time.
\end{abstract}

Keywords: religion; atheism; hope; contingency; justice; immortality 
El Dios digno de ser esperado es aquel que tiene la excusa de no existir.

Quentin Meillassoux

Quizá el ASUnto más polémico, para algunos incluso escandaloso, de la propuesta de Quentin Meillassoux -filósofo francés nacido en 1967, creador del "materialismo especulativo" 1 - es la recuperación que hace de ideas religiosas, hilo conductor de alguna forma de su tesis de doctorado, Linexistence divine $e^{2}$ y del breve ensayo "Dios por venir, duelo por venir", del que existen al menos dos versiones en español (Meillassoux, 2016; 2018a). En este ensayo nos proponemos exponer e intentar explicar el significado y el valor precisos de la filosofía de la religión del pensador francés. Específicamente, nos ocupamos del sentido, ni religioso ni ateo, de su propuesta de "irreligión" (no-religión) filosófica. Consideramos que este planteamiento tiene un carácter original respecto a diversas propuestas sobre el mismo asunto dadas en la historia de la filosofía y en la filosofía contemporánea. No pretendemos retomar todo lo que se ha dicho hasta ahora sobre la relación entre filosofía y religión, sino solamente algunos referentes que resultan significativos para nuestra exposición.

A pesar de su carácter escandaloso o extraño, nos proponemos defender la cordura e incluso la pertinencia filosófica del planteamiento de Meillassoux, tratando de precisar el sentido de su concepción frente a ciertas confusiones a que puede dar lugar. Primeramente, cabe aclarar que se trata de un "proyecto", puesto que la filosofía del pensador francés, y particularmente su idea de una

1 Este es el concepto que propiamente utiliza Quentin Meillassoux para designar su filosofía desde Après la finitude (2006). A partir del Coloquio en la Universidad de Londres de 2007, en el que participaron además de Meillassoux, Graham Harman, Ian Hamilton Grant y Ray Brassier, se usó, a propuesta del último, el concepto de "realismo especulativo". Posteriormente Markus Gabriel y Maurizio Ferraris crearon el término "nuevo realismo". Todos estos autores tienen en común la crítica al idealismo subjetivista moderno y la recuperación de la ontología, y como antecedente principal el planteamiento inicial de Meillassoux. Véanse Bryant, Srnicek \& Harman, 2010; Ramírez, 2016; Gratton \& Ennis, 2015; Brassier, 2017; Harman, 2018; Ferraris, 2013.

2 La tesis, inédita, data de 1996 (el examen se realizó en enero de 1997) y la copia microfilmada que se encuentra en la Biblioteca Nacional de Francia es accesible por internet. Entre otros portales, se puede leer en Scribe. Lo citaremos en adelante así: Meillassoux, 1997. Aparecen extractos de esta tesis en el libro de Harman, 2011. Traduzco del francés para comodidad del lector las citas de esta obra y de otros textos de Meillassoux no publicados en español. 
síntesis de racionalidad filosófica y esperanza religiosa, se encuentra en proceso -una "philosophy in the making"-, como subtituló Graham Harman (2011) su introducción al pensamiento de Meillassoux. Ahora bien, puesto que la primera exposición de este proyecto data de 1996, en la tesis de doctorado ya referida, y desde entonces, quizá por su exigente rigor, el filósofo francés solo ha publicado dos libros (Meillassoux, 2015 y 2011), es probable que ese proyecto permanezca como tal y el autor no lo retome más, dejándonos a sus lectores la tarea de dilucidarlo y explayarlo, si es que nos es posible. Puede ser que el proyecto de síntesis filosofía-religión sea al fin insostenible. No obstante, algunas enseñanzas puede dejarnos mientras nos abocamos al intento de comprenderlo y pensarlo. En este sentido, nuestro ensayo no se propone ni ser una exposición estricta y exhaustiva de la postura de Meillassoux ni ser una crítica desde alguna perspectiva distinta o contrapuesta. Buscamos comprender ideas fundamentales de su planteamiento poniendo en juego nuestra propia comprensión y nuestras preocupaciones filosóficas. Nuestro propósito se puede resumir como un intento de responder a la pregunta: ¿cuál es el sentido de la propuesta del filósofo francés en el contexto general de la historia de la filosofía e incluso de la historia cultural de la humanidad?

De esta manera, después de (1) un planteamiento básico y general sobre la filosofía de Quentin Meillassoux, que aborda los conceptos de materialismo radical e inmanencia total en el marco de su filosofía irreligiosa, analizamos cuatro temas de su planteamiento: (2) religión, irreligión y esperanza; (3) Dios y lo "divino"; (4) razón, contingencia y fe; y (5) razón especulativa y razón práctica (ética divina). Finalmente, a manera de conclusión, (6) exponemos la refutación del "nihilismo" que propone el filósofo francés, por ser, de cierto modo, el fenómeno cultural que está en juego en el atolondrado momento histórico que nos toca vivir.

1. Materialismo radical e inmanencia total. La filosofía irreligiosa de Meillassoux

Como el propio Meillassoux explica, el título de su tesis de doctorado, La inexistencia divina, tiene un significado complejo. No quiere decir solamente, aunque también, que Dios no existe, sino aún más, si calamos en el sentido del adjetivo "divino", que la inexistencia de Dios tiene en cuanto tal, un 
carácter divino (Meillassoux, 1997; ver resumen inicial). Esto quiere decir que "no existir" es la mejor cualidad de Dios, el rasgo que mejor le va. De ahí el lema paradójico de la filosofía irreligiosa de Meillassoux: "creer en Dios porque él no existe”, o "creer en un Dios que no existe” (¡eso es fe!), formulación inédita que se distingue de las que han existido hasta ahora: "creer en Dios porque él existe" (la religiosa), "no creer en Dios porque él no existe" (la atea), y "no creer en Dios porque él existe” o "no creer en Dios aunque él exista” (la del demonismo, el cinismo, el nihilismo) (Meillassoux, 1997, pp. 388-389). Es necesario calar en el significado del desafío filosófico que el pensador francés nos lanza.

Desde el título de su trabajo, Meillassoux rehúye la alternativa tradicional que nos lleva a tener que escoger entre afirmar la existencia de Dios (religión) o negarla (ateísmo, nihilismo), con la idea de que la inexistencia de Dios puede ser considerada todavía como "divina", esto es, como un modo propio, o el modo propio de ser de lo divino. En todo caso, la inexistencia de Dios deja abierta la posibilidad futura de su existencia -lo que llama el Dios virtual ${ }^{3}$-, o bien, que Dios subsista en el campo de las posibilidades, de su inexistencia actual y de su existencia virtual como la mejor cualidad que puede corresponderle. Trataremos de mostrar en este ensayo la racionalidad de estas tesis y de la extraña aseveración de que "Dios no existe todavía" (Meillassoux, 2016, p. 106).

$\mathrm{Al}$ proponerse Meillassoux hablar realistamente, incluso en términos materialistas, de Dios, de espectros o fantasmas, del "duelo esencial", el reino de la justicia plena, la "resurrección de los cuerpos", la recuperación de la esperanza escatológica o de la fe como posibilidades reales y no como cosas del ultramundo o como ficciones mistificadoras e ideológicas, algunos podrían llegar a dudar de la cordura de este pensador que, por otra parte, se asume como un defensor a ultranza de la recuperación de la razón pura en filosofía -lo que significa la palabra "especulativo" en su propuesta de materialismo especulativo-. El colmo o el punto límite de una postura materialista - digamos que su prueba de fuego- consiste en incluir a Dios como un ente posible en este mundo, un dios real que lleva el inmanentismo y el materialismo filosóficos a un nivel de coherencia absoluta. Ninguna trascendencia o misterio queda entonces para esta filosofía que busca

3 Meillassoux tiene en cuenta como antecedente, aunque radicalizando su significado, el concepto de virtualidad propuesto por Gilles Deleuze (Deleuze, 2012, pp. 314 y ss.; Ramírez, 2016, pp. 193-210). 
llevar la razón a sus últimas consecuencias. En este sentido, el materialismo de Meillassoux se encuentra en la línea del "ateísmo materialista” que viene de los antiguos pensadores materialistas griegos, Empédocles, Epicuro, Lucrecio, pasa por Spinoza, Hegel y el joven Marx, y llega a Ernst Bloch y otros pensadores del siglo Xx. El materialismo del filósofo francés debe verse más como una filosofía radical de la inmanencia que como un reduccionismo mecanicista y naturalista a la manera de cierto materialismo pretendidamente científico. Meillassoux nos recuerda, en todo caso, el carácter crítico, obligadamente combativo, del materialismo y, relevantemente, su significado y cometido ético.

Ciertamente el proyecto de recuperación filosófica de temas de corte religioso por parte de Meillassoux resulta extraño, por decir lo menos, no solamente en virtud de lo que normalmente entendemos por filosofía, sino también en relación con cierto espíritu de nuestra época, muy crítico y bastante escéptico y descreído respecto a cualquier planteamiento de reasunción de lo religioso. Es verdad, sin embargo, que en el campo de la filosofía se dio en el fin del siglo pasado una proliferación de filosofías de lo religioso -en la fenomenología francesa, por ejemplo ${ }^{4}$ - pero bajo un tipo de enfoque que apuntaba discreta o abiertamente a un restablecimiento de la postura religiosa tal cual, posición que Meillassoux rechaza tajantemente, como rechaza también las posturas meramente ateas que dan la espalda inmediatamente, y dogmáticamente, a cualquier planteamiento filosóficamente serio sobre el tema de Dios. Encontrar una tercera vía, más acá de la mistificación religiosa y más allá del nihilismo y la deflación atea, parece una tarea compleja, improbable, y de la que existen pocos antecedentes en la historia de la filosofía. Precisamente esto hace de la propuesta de Meillassoux algo retador y significativo. ¿En qué puede consistir esa tercera vía? ¿Cómo debe construirse? ¿Cuáles pueden ser sus supuestos y sus implicaciones, sus consecuencias? Téngase en cuenta que se trataría de una vía estrictamente racional y, si no científica, al menos no contradictoria con los conocimientos científicos.

4 Considérense autores como Jean-Luc Marion, Michel Henry, y otros. El tema religioso ha estado lateralmente presente en la fenomenología desde Husserl y Heidegger (Roggero, 2017). 
EN PRIMER LUGAR, hay que tener claro que Meillassoux transfigura y redefine conceptos básicos de la tradición filosófica, y en esto radica inicialmente el rasgo propio de su filosofía. Conceptos tales como realidad, razón, ontología, contingencia, existencia, devenir, y, claro, ética, esperanza, religión, Dios y otros, no pueden seguir entendiéndose solo en el sentido en que hasta ahora se han usado. El filósofo francés opera un giro fundamental en el alcance de estos conceptos. Así, cuando recupera ciertas nociones de la religión, lo hace desde una perspectiva radicalmente crítica -en consonancia con el espíritu básico de la filosofía y con la línea dominante, crítica y desmitificadora, del pensamiento filosófico y científico de la modernidad-. Meillassoux considera, en todo caso, que existe un valor o una verdad ínsita en el pensamiento religioso, pero que las religiones oscurecen o son incapaces esencialmente de explicar, de sostener y mantener. Por eso, para definir su propio proyecto, opta por usar el término "irreligión", que no significa antirreligión. Como dice Meillassoux: "la irreligión filosófica no es un ateísmo, sino la condición para un acceso auténtico a lo divino” (Meillassoux, 2009, p. 39). Esto significa que la filosofía, ocupándose del tema religioso, resulta más atinada y verdadera que la propia religión, es decir, resuelve mejor las cuestiones que esta última plantea y de las que ni siquiera puede calibrar todo su sentido y alcance. Esto, que ya podía verse en las filosofías de Spinoza y Hegel, por mencionar dos ejemplos paradigmáticos, resulta meridianamente claro en la filosofía de Meillassoux.

Análogo al concepto de "irrazón" -también propuesto por Meillassoux-, que no significa una pura negación de la razón sino la afirmación racional radical de la contingencia del ser, "irreligión" tampoco significa una mera negación, sino la afirmación de la más alta y racional comprensión de lo divino. Irreligión es un procedimiento estrictamente filosófico mediante el cual negamos la religión, y claramente todas las religiones existentes, pero afirmamos y recuperamos en un nivel superior, es decir, filosófico, el núcleo de sentido y verdad que ella contiene, su "núcleo racional", como podrían decir Hegel o el joven Marx5. ¿Cuál es ese

5 Es famosa la afirmación de Marx de proponerse encontrar "el núcleo racional" de la filosofía idealista de Hegel como medio para la elaboración de su teoría económica materialista. Véase Marx, 
núcleo válido y de alguna forma irrenunciable de la religión, específicamente de lo "divino", de esa esencia divinológica que trasciende incluso a la misma cuestión sobre la existencia o no de Dios, según Meillassoux? No otro precisamente que la escatología, esto es, la esperanza en la justicia plena, el deseo absoluto de justicia (de Bien), que no escatima nada y no deja a nadie fuera. Esta concepción es más cercana a la valoración humanista y atea que hace Marx -y luego Ernst Bloch- del cristianismo ${ }^{6}$ que a la interpretación especulativa que hace Hegel más interesado en construir una interpretación racional del mundo que en su transformación efectiva (Hegel, 2010, pp. 431 y ss.; Hegel, 1981)-.

El punto es que las religiones son incapaces de sustentar y mantener la esperanza en un mundo de justicia y el deseo absoluto de bien de forma consistente y congruente. Su equívoco consiste, según Meillassoux, en afirmar que Dios existe, y existe necesaria y absolutamente -no queda ningún resquicio-, lo que implica que las religiones deben incluir como parte de ese Dios, de su naturaleza propia, el mal existente en el mundo. De ahí que el filósofo francés juzgue como la mayor de las blasfemias la suposición de que Dios existe, el Todo-poder que, contradictoriamente, puede incluso el mal, o que pudiéndolo evitar lo deja existir (es la famosa "paradoja del mal" atribuida tradicionalmente a Epicuro ${ }^{7}$ ). Dice Meillassoux (1997):

1999, p. 20, y también Caligari y Starosta, 2015. Por nuestra parte, generalizamos este procedimiento -buscar el "núcleo racional" - para interpretar las propias posturas de Hegel y Marx respecto al cristianismo y la religión en general. Es un tópico en la filosofía poshegeliana interpretar la dialéctica hegeliana como una elaboración filosófica de la trinidad cristiana (el Padre, el Hijo y el Espíritu Santo). El vínculo de Marx con el cristianismo ha sido tema de muchas elaboraciones y discusiones. En nuestro continente dio origen a las corrientes de la teología y la filosofía llamadas “teología de la liberación” y “filosofía de la liberación”. Entre otros, véase Dussel, 1993.

6 Según Bloch, cristianismo y ateísmo mantienen en verdad una relación dialéctica: "solo un ateo puede ser un buen cristiano, pero ciertamente también: solo un buen cristiano puede ser un buen ateo" (Bloch, 1983, p. 16). En general, podemos considerar la filosofía materialista de la esperanza y la ontología del "todavía-no" (lo virtual) de Bloch como un antecedente de la postura de Meillassoux, aunque con sus importantes diferencias (Bloch, 2004-2007).

7 Así lo hace David Hume (1994) en el siguiente pasaje: "Las viejas cuestiones de Epicuro continúan sin encontrar respuesta. ¿Quiere él [Dios] prevenir el mal, pero no puede?, entonces es impotente. ¿Puede, pero no quiere?, entonces es malévolo. ¿Puede y quiere?, entonces de dónde sale el mal?” (p. 149). 
Decir que Dios existe es la peor de las blasfemias, pues es decir que Dios reina sobre el mundo como un dictador, sin haber tenido jamás la debilidad de modificar sus designios a fin de acabar las atrocidades en curso. Es decir que este mundo es tal que Dios lo ha querido en sus proyectos, proyectos impenetrables para el hombre justo, por ser de una crueldad efectivamente incomprensible (p. 394) ${ }^{8}$.

La esperanza religiosa se convierte en un sentimiento irracional, en una conciencia mistificada, en un puro mecanismo ideológico de control de las personas. El punto es que la esperanza queda condicionada en la religión a la aceptación de que la resolución de las problemáticas humanas, el alcance de la justicia plena, solo será posible en el otro mundo, el mundo suprasensible o supranatural, el cielo, el "más allá", el "paraíso", etcétera. Tal es la condición estructural de todo pensamiento religioso, que es producto más de una incertidumbre, una desconfianza -y al fin una negación- frente al mundo existente, que de una verdadera afirmación del deseo de justicia y plenitud. La religión ha sido el gran equívoco del espíritu humano. Sobre todo si consideramos sus grandes promesas, las grandes expectativas que genera y con las que se ha justificado -y ha justificado las peores atrocidades- hasta hoy. Su problema es que no se toma en serio verdaderamente -el religioso es el primer incrédulo-; de ahí que el nihilismo, como pensaba Nietzsche9, ya está incubado en el regazo de toda concepción religiosa. Lanzar hacia un más allá de este mundo la resolución de nuestros pesares es esencialmente una manera de aceptarlos, de conformarse con soportarlos, de hacer de la negación de la vida el sentido de la misma vida.

La filosofía del "Dios por venir" de Meillassoux se puede interpretar como una nueva respuesta, quizá definitiva, a la paradoja teológica del mal.

8 «Dire que Dieu existe c'est le pire desde blasphèmes, car c'est dire que Dieu règne sur ce monde en grand politique, sans avoir jamais eu la faiblesse de modifier ses desseins afin d'empêcher les atrocités qui y ont cours. C'est dire que ce monde est tel que Dieu l'a voulu en ses projets, projets impénétrables pour l'homme juste, parce que d'une cruauté effectivement incompréhensible. »

9 Una postura recurrente en Nietzsche es considerar a las religiones y particularmente al cristianismo como origen y esencia del "nihilismo" (por su "negación" del cuerpo, el placer, la vida, el mundo). Véase el texto paradigmático de Nietzsche, El anticristo. Maldición sobre el cristianismo, 1974. No obstante, el tema del nihilismo en Nietzsche es complejo y admite varias acepciones o momentos (Frey, 2009). 
La tajante visión dualista del mundo -mundo divino, supranatural, y mundo humano, natural, terrenal- propia de la religión y de la metafísica, concebida en términos estáticos, fue aligerada por la concepción judeo-cristiana que introdujo la dimensión temporal-teleológica, la primera "filosofía de la historia" ${ }^{0}$ : el mundo de la salvación, la felicidad y la justicia no solo está arriba sino también adelante, en el porvenir: en el fin de la historia -humana, de sufrimiento- y el arribo al reino de Dios. Este giro, esta concepción "histórica" de la relación entre lo divino y lo humano permitió que hubiera un lugar -aunque menor- para la acción y la libertad humanas: el acceso al reino celestial no dependerá únicamente de inescrutables leyes divinas sino, en alguna medida, de la acción de la humanidad en su devenir. Ciertamente, para la concepción cristiana la "gracia" viene finalmente de Dios y el humano solo la recibe, aun sin merecerla. La salvación no depende de nosotros sino de la decisión divina. Libertad, lo que se dice libertad, solo la posee Dios. De ser una religión que quería salvarnos de toda religión, el cristianismo quedó convertido en la más poderosa y mistificadora de las religiones, aun -ya como catolicismo- con su carga de sincretismos, ambigüedades y mundanidades.

¿Es posible desde la filosofía recuperar la idea de esperanza en un sentido racional? ¿Es posible acabar ahora sí y en definitiva con la religión y toda su cauda de equívocos y contradicciones, con el dogmatismo, el fanatismo, la irresponsabilidad moral que se sigue de su desorden conceptual e institucional? La respuesta afirmativa a esta cuestión es la gran apuesta de Meillassoux: liberarnos por fin de la religión y, a la vez, de esa forma nihilista de religión que es el ateísmo. Esto es, liberarnos de toda religión, que es decir de todo mito de la "necesidad", todo "determinismo", sea el del ser supremo de las religiones existentes o el de las leyes inmutables de la naturaleza o de la historia de la religión atea ${ }^{11}$.

10 El "mesianismo" -el arribo de un salvador en algún momento futuro-, común al judaísmo y al cristianismo, es la idea clave que introduce una visión histórica en la vicisitud humana. Se considera que San Agustín elaboró la primera "filosofía de la historia”, aunque se trata propiamente de una "teología de la historia" (Pegueroles, 1972, pp. 99-126).

11 La crítica del determinismo tiene un alcance radical en Nietzsche (2010). "Somos nosotros, y únicamente nosotros, quienes hemos inventado, como tantas ficciones, la causa, la sucesión, la reciprocidad, la relatividad, la necesidad, el número, la ley, la libertad, la razón, el fin; y cuando introducimos falsamente en las cosas este mundo de signos inventados por nosotros, cuando lo incorporamos a 
Debe quedar claro que Meillassoux no propone un retorno a lo religioso, como en el que varios intelectuales desde fines del siglo XX se han embarca$\mathrm{do}^{12}$. Todo lo contrario de cualquier retorno, lo que Meillassoux propone -una filosofía irreligiosa, o una irreligión filosófica- significa la clausura definitiva del pensamiento religioso y de toda forma de religión. Tampoco, cabe aclarar, está proponiendo una mera sustitución de las religiones establecidas por una nueva religión, dizque filosófica y racional. Se trata, solamente, de dar todo su sentido y potencia al pensamiento filosófico, a la Filosofía -es decir, eso con lo que soñaron aquellos grandes de la filosofía moderna como Descartes, Spinoza, Kant, Hegel-. Al contrario del intento de la filosofía medieval de someter la filosofía a la religión, de priorizar la fe sobre la razón ${ }^{13}$, ahora se trata de priorizar la filosofía sobre la religión, y al fin, de disolver la religión en el movimiento de una razón filosófica radicalmente esclarecida. En la lucha entre religión y filosofía no hay tercer término, dice Meillassoux (1997, p. 377): o hay una unidad religiosa entre religión y filosofía -como lo que se propuso en el pasado y hoy proponen quienes desean un retorno a lo religioso-, o hay una unidad filosófica entre religión y filosofía -que es la propuesta del pensador francés-. El asunto debe ser visto en gran perspectiva histórico-intelectual y cultural:

las cosas como si les perteneciese 'en sî', obramos una vez más como lo hemos hecho siempre: creamos una mitologia" (p. 405). No obstante, Meillassoux se propone matizar el radicalismo nietzscheano, todavía nihilista, mediante la restauración de una ontología racional y consistente.

12 Como una muestra del interés en lo religioso de algunos filósofos relevantes de la segunda mitad del siglo xx: Derrida y Vattimo, 1997; en el que aparecen además textos de Maurizio Ferraris, Hans-Georg Gadamer, Aldo Gargani, Eugenio Trías y Vicenzo Vitiello. En los grandes pensadores del siglo xx que dan un lugar a la "mística" -Wittgenstein, Heidegger, Adorno, Levinas- lo que domina más bien es una especie de "teología negativa”, donde Dios se define más en términos negativos que positivos (el silencio, lo inefable, lo indeterminable, lo inaprehensible, etc.), lo cual, por otra parte, no es nada nuevo en cuanto pensamiento teológico-filosófico. Meillassoux se deslinda de esta postura por considerarla tendencialmente irracionalista, lo que deja abiertas las puertas al fideísmo, el fanatismo o el nihilismo, sus adversarios principales.

13 Como sostiene Gilson, la filosofía medieval solo acepta la independencia entre fe y razón bajo la expectativa de que el conocimiento racional bien orientado conduce a Dios: "la razón puede, mediante la inteligencia y partiendo del espectáculo de las obras divinas, conocer la existencia de Dios, su eterno poder, y otros atributos más que nombra” (Gilson, 1965, p. 14). Pero no hay alternativa. Si un conocimiento racional no conduce a Dios es que no estaba bien orientado. La fe tiene, pues, prioridad sobre la razón. 
Se puede resumir así la apuesta esencial del pensamiento occidental: ¿cómo pensar la unidad de la religión judía y la razón griega? Todo el problema radica en el hecho de que Occidente, pero también Oriente, acepta estas dos 'verdades' heterogéneas -y ni una más-. Pues ecómo pensar la unidad del mesianismo, que rompe con el tiempo cíclico de las mitologías paganas (tiempo no igualitario, sin promesa), y la eternidad racional, matemática y filosófica, de los Griegos? (Meillassoux, 1997, p. 377) ${ }^{14}$.

La unidad filosófica de filosofía y religión encuentra su tema en el concepto de esperanza. ¿Puede este concepto, consustancial a la humanidad, ser asumido de manera filosóficamente plena y fructífera? Una forma de remarcar el carácter filosófico consiste en afirmar que la esperanza radical no es aquella que conciben las religiones, sino el concepto de esperanza tal como es recuperado desde la filosofía, es decir, como una esperanza factual, como una esperanza racional que se sustenta en una ontología de la contingencia y del devenir absolutos -la propuesta de Meilassoux-, que cuestiona, pues, toda idea de necesidad, religiosa, atea o supuestamente científica. Como asienta Meillassoux (1997):

La esperanza consiste precisamente en la intuición de un surgimiento posible que excede toda probabilización. Quien espera, espera de manera siempre irrazonable lo que excede las condiciones probables, "posibles", del tiempo presente - lo que rompe con la constancia actual del mundo. Y la esperanza no puede ser identificada con una simple quimera, con un deseo caprichoso entre otros, porque su desmesura trata de la justicia. Pues lo que esta desmesura de la esperanza manifiesta de aqui en adelante es el conocimiento mismo de la desmesura del devenir (p. 339) $)^{15}$.

14 «On peut résumer ainsi l'enjeu essentiel de la pensée occidentale: comment penser l'unité de la religion juive et de la raison grecque? Tout le problème tient dans ce fait que l'Occident, mais aussi l'Orient, accueillent ces deux "veritées" hétérogènes - et pas une de plus. Car comment penser l'unité du messianisme égalitaire des juifs, messianisme rompant avec le temps cyclique des mythologies païennes (temps inégalitaire puisque sans promesse), et de l'éternité rationnelle, mathématique et philosophique, des Grecs?»

15 «L'espoir consiste précisément dans l'intuition d'un surgissement possible excédentaire de toute probabilisation. Celui qi espère, espère de façon toujours déraisonnable ce qui excède les conditions probables, voire "possibles", du temps présent - ce qui rompt avec la constance actuelle du monde. Et l'espoir ne peut être identifié à une simple chimère, à un désir capricieux parmi d'autres, parce que sa démesure 
Es decir, la esperanza, nuestra esperanza en un mundo mejor, en un mundo de justicia plena, puede ser fundamentada racional y ontológicamente. Lejos de ser un mero sentimiento producto de la desazón ante la existencia presente, se convierte en la expresión de un conocimiento profundo - una verdadera gnosisen la que se aprehende el carácter ontológicamente abierto e inacabado de toda existencia. De ser un puro consuelo para el sufrimiento y la desesperación, la esperanza se transforma en una verdad filosófica de primer orden. Otro mundo es posible, cierto: contingentemente posible.

3. Dios y lo "divino": justicia plena

Esencial en el pRoyecto de Meillassoux es la manera como hemos de entender la noción de Dios -hay que recordar que los filósofos se han ocupado desde siempre de esta noción (Aristóteles, Tomás de Aquino, Descartes, Spinoza, Schelling, Hegel, Levinas, etc.); y que si ella tiene y ha tenido algún sentido consistente ha sido gracias a ellos-. Los pobres teólogos se encuentran siempre en sus exploraciones intelectuales sobre Dios con que tenían que haber creído en Él desde el principio, antes de iniciar cualquier exploración. ¿Entonces para qué exploro?, podrían preguntar con razón siempre.

La cuestión de Dios y de la esperanza en un sentido absoluto la expone Meillassoux a través de un cuestionamiento sobre el destino de las "muertes injustas", o las muertes claramente injustas: por ejemplo, de niños por cáncer o SIDA, de jóvenes en accidentes terribles, de personas que no habían cometido ningún delito o incluso de luchadores de causas justas, etc. Estas muertes -según los ejemplos de Meillassoux (2016): "muertes precoces y muertes odiosas, muerte del niño, muerte de padres que saben que sus hijos correrán la misma suerte” (p. 101) - nos ponen en la situación de la "imposibilidad del duelo"; los muertos injustamente son esos espectros o fantasmas que se resisten a pasar al otro lado y que nos acosan y perturban: ¿cómo hacer el duelo de estos muertos? (esto es

porte sur la justice. Car ce que cette démesure de l'espoir manifeste désormais, c'est la connaissance même de la démesure du devenir. » Así pues, en su máxima expresión, como facultad de esperar lo "imposible", la esperanza puede ser fundada racionalmente en una ontología de la inmanencia, el devenir total y la contingencia absoluta, como la que propone Meillassoux. Nada hay imposible en el ser en cuanto tal. 
el "duelo esencial"; Meillassoux, 2016, p. 102). Solo tenemos dos respuestas: la religiosa y la atea. Bien aceptamos que las muertes injustas son el producto de un Dios injusto que se presenta contradictoriamente como el justo por excelencia, o bien asumimos, con el ateo, que no hay nada que hacer: asumimos que la justicia plena es imposible en este mundo y en cualquier otro. El cuestionamiento por el duelo esencial nos lleva así al cuestionamiento por la existencia de Dios.

Según Meillassoux, el problema con la existencia de Dios, para afirmarla o para negarla, es que le antecede siempre la asunción de la categoría omnipresente de "necesidad": Dios debe existir o Dios no debe existir, la postura religiosa y la postura atea, respectivamente. De esta manera la decisión ya está tomada a priori. El religioso y el ateo coinciden esencialmente: ambos otorgan a su postura un carácter de definitividad e indiscutibilidad: ambos son dogmáticos. Y ambos aceptan de principio la imposibilidad de la justicia plena, para vivos y muertos. Por esto la respuesta meramente atea no le basta a Meillassoux. Ella cojea igual que la respuesta religiosa, en la medida en que el ateísmo termina siendo una postura que niega más de lo que afirma (su fórmula predilecta es: "no hay más que esto"; su inmanentismo se convierte en un reduccionismo, y su "humanismo" en idolatría). Por el contrario, la respuesta del filósofo francés es que hay una tercera opción. Meillassoux la expresa con la sorprendente fórmula: "Dios no existe todavía"16. Lo que en esta opción "está en juego -precisa el pensador francés- es desligar el lazo ateo-religioso entre Dios y la necesidad (Dios debe o no debe existir) para religarlo a lo virtual (Dios puede existir)" (Meillassoux, 2016, p. 106).

Dios es una posibilidad a futuro, "Dios virtual" que no es el puro objeto de una fe, sino de un razonamiento estrictamente filosófico, bajo una nueva perspectiva

16 La fórmula puede desglosarse, según él, en dos cuestiones, en "dos polos de significación que deberían entonces estudiarse por turno": "1. ¿Qué significa el 'todavía' para que un dios pueda ser pensado como una de sus eventualidades? Tal examen remite a pensar la significación de un tiempo compatible con el duelo esencial: ¿qué es el tiempo, si este contiene lo divino como una de sus virtualidades, y qué es lo que puede legitimar nuestra creencia en la efectividad de esta? 2. ¿Qué significa precisamente el significante 'dios' una vez que este es puesto como todavía no existente, posible y por venir y ya no actual y necesario? Tal examen impondría, de forma relevante, elaborar los elementos de un discurso sobre lo divino distinto al de toda teología fundada sobre la tesis de un Dios eterno" (Meillassoux, 2016, p. 107) 
ontológica que Meillassoux condensa en la idea de contingencia absoluta, es decir, en negación de toda necesidad (parcial o absoluta, de Dios o de las leyes de la naturaleza ${ }^{17}$ ). Dada la contingencia radical no se puede negar la posibilidad de la emergencia de Dios en un futuro, aunque no hay nada que asegure esto, no hay ninguna necesidad, ni hacia atrás ni hacia adelante. Dios puede llegar a existir, o puede no. Y esta posibilidad no depende de nada ni nadie y menos de nosotros, los humanos; solo depende de la contingencia y capacidad de innovación absoluta del devenir inmanente, sin ley ni fin.

Más allá de los argumentos lógicos, ontológicos y antropológicos que se han presentado en la historia de la filosofía en contra de la suposición de la existencia de Dios, en filósofos como Spinoza, Hegel o Heidegger (Dios no puede ser un "ente", coinciden los tres ${ }^{18}$ ), Kant (no se puede deducir la existencia real de un ente de su existencia ideal ${ }^{19}$ ), Feuerbach (Dios es solo la autorrepresentación de humanidad genérica ${ }^{20}$ ), Meillassoux presenta una crítica ético-ontológica. "Dios" no es solamente un ente contradictorio desde un punto de vista lógico y ontológico sino, sobre todo, desde un punto de vista ético: la religión nos pide reverenciar a un Dios que, por lo menos, no tiene clara la distinción entre lo justo y lo injusto, entre el bien y el mal. El Dios por venir de Meillassoux quizá no sea omnipotente y omnisciente, pero es claro que deberá ser absolutamente bondadoso, bondadoso sin duda, en cuanto no será de ninguna manera "causa" del mal en el mundo.

17 Meillassoux (2015) no niega que existan leyes en la naturaleza, niega que tengan un carácter absoluto, pues esto implicaría que hay una "ley de leyes", la que otorgaría ese carácter; como no hay tal, las leyes son "regularidades contingentes".

18 Dios no es un ente, Dios es el "todo", la "totalidad". Bien como totalidad positiva, unidad de Dios y la naturaleza, en Spinoza; bien como totalidad dialéctica, como "espíritu absoluto" en Hegel; o bien como totalidad "ausente", en Heidegger. Sin embargo, aunque son los grandes pensadores de la inmanencia atea (los tres son discutidos por Meillassoux, 1997 y 2015), ninguno pone en cuestión el principio de "necesidad": el todo es lo necesario en sí. Operar a partir del principio de la contingencia absoluta de lo que existe, que no es "totalizable", es lo que marca la diferencia del inmanentismo de Meillassoux con todo inmanentismo anterior.

19 Tal es la crítica que hace Kant del llamado "argumento ontológico" sobre la existencia de Dios ( $K r V: \mathrm{A} 592 / \mathrm{B} 620-\mathrm{A} 602 / \mathrm{B} 630)$.

20 "Lo que el hombre dice de Dios, lo dice en realidad de sí mismo" (Feuerbach, 1941, p. 40). 
Ahora bien, el punto relevante en la divinología no es la expectativa en la aparición efectiva de Dios en el futuro sino solamente el hecho de no descartar esta posibilidad, de contar con ella como una posibilidad objetiva y no meramente subjetiva (y esto es lo que significa "divinología", lo "divino", en Meillassoux). En cuanto esa posibilidad ya está presente como tal -en el hipercaos, en el campo de virtualidades ${ }^{21}$ - podemos asumir que lo divino existe de alguna manera. $\mathrm{Su}$ símbolo es, para Meillassoux, el "niño", en cuanto anuncio de la posibilidad del renacimiento, del "rebautizo", esto es, de la emergencia de la "novedad radical", de algo nunca dado y nunca previsto. El niño que tiene todo su ser hacia adelante y que ni siquiera lo sabe, que nada sabe de lo que podrá llegar a ser: solo tiene los ojos vivamente, felizmente abiertos.

\section{Fe, razón y contingencia}

¿Tiene SENTIDO HablaR de una "fe racional", de una síntesis de fe y razón? ¿Qué significado y función debe tener la razón, la racionalidad, para una posible compatibilidad entre fe y razón? Aquí resulta importante precisar el concepto de razón, de razón pura o razón especulativa, que Meillassoux ha reivindicado, en lo que puede denominarse, hablando de Francia, un "neocartesianismo", precedido de un "antikantismo". Precisamente, el signo del filósofo francés, y de varias figuras del realismo especulativo (como Harman, 2015; Gabriel, 2017; y Ferraris, 2013) es su desobediencia al dictado kantiano de los "límites de la razón", que proscribía la posibilidad de la metafísica o de la ontología, es decir, toda filosofía sobre el ser en sí, sobre lo que está más allá de nuestra experiencia. Este escepticismo, este agnosticismo, condujo de alguna manera al relativismo generalizado, al nihilismo, incluso a la idea de "posverdad" de nuestros días, y al entronarse de posturas irracionales, fanáticas y hasta terroristas. Frente a esta condición, la condición posmoderna propiamente, es necesario recuperar la razón en un sentido

21 Véase el apartado "Potencialidad y virtualidad" en Hipercaos (Meillassoux, 2018b). Mientras que la potencialidad designa las posibilidades predeterminadas dentro de un sistema, la virtualidad es la posibilidad de la "emergencia radical". "Denomino virtualidad a la propiedad de todo conjunto de casos para emerger dentro de un devenir que no domina ninguna totalidad preconstituida de posibles" (pp. 109-110). Meillassoux (2007a) defiende la postura del "emergentismo": surgimiento de algo -la materia, la vida o la conciencia- desde la nada (pp. 52-69). 
fuerte. Meillassoux aboga por la recuperación de una racionalidad dianoética o razón intuitiva, más allá de la razón dogmática y de la mera razón formal e instrumental, esto es, una razón capaz de darnos verdades y verdades absolutas acerca del ser. ¿En qué consiste la razón dianoética, según el pensador francés? (Meillassoux, 2015, p. 134; y Meillassoux, 2007b).

La propuesta de racionalidad de Meillassoux supone asumir un principio de convergencia entre razón y realidad (o materialidad), y este es el principio lógico de no contradicción en cuanto principio lógico y a la vez ontológico. Ahora bien, Meillassoux acepta la validez absoluta del principio de no contradicción porque asume la falsedad absoluta del principio metafísico de razón suficiente, según el cual ha de existir una razón para cualquier cosa y para el todo mismo.

Aceptar el principio de no contradicción implica, según Meillassoux, rechazar la idea de necesidad, y por ende la idea de ser necesario, pues un ser necesario es un ser lógicamente contradictorio. Por eso, para Hegel, siendo consistente con su proyecto filosófico, aunque en contra de la lógica elemental, la contradicción era la necesidad absoluta, o lo necesario debía ser contradictorio, ser la contradicción misma ${ }^{22}$. Por el contrario, para Meillassoux, solo el ente contingente y temporal, el ente existente, es no-contradictorio, pues solo él puede ser dos cosas distintas sin contradicción - porque no las es al mismo tiempo, mientras que ser al mismo tiempo dos cosas distintas es el carácter del ser necesario, intemporal o eterno (Meillassoux, 2015, p. 114)-. Así, a la vez que entrona el principio lógico de no contradicción como principio ontológico, Meillassoux desecha críticamente el principio metafísico de razón suficiente (p. 116), el cual supone, precisamente, el principio de causalidad necesaria -todo tiene una causa- y, al fin, el principio de existencia necesaria, esto es, la existencia del ente necesario. Quedarnos con el principio de no contradicción como condición de posibilidad a la vez del acto pensar y de la existencia del ente implica desechar el principio de necesidad, el principio teológico-teleológico: la ontoteología.

La negación de la idea (la ficción, en realidad) de ente necesario nos permite arribar a una filosofía que es capaz de otorgar toda su legitimidad ontológica a la

22 "No es una casualidad si el mayor pensador de la contradicción -a saber, Hegel- fue un pensador no del devenir soberano, sino por el contrario de la identidad absoluta, de la identidad de la identidad y la diferencia" (Meillassoux, 2015, p. 115). 
existencia, a la realidad, y que, de esta manera, es capaz de justificar plenamente la verdad y el valor del pensamiento científico, mucho más en serio que todos los intentos de la epistemología moderna. Precisamente, en cuanto tuvo como condición la aceptación del dogma escéptico kantiano, toda la epistemología positivista y neopositivista se contentó con una validación "relativa" del saber científico, remitiéndose únicamente a las condiciones de producción de tal saber, y eliminando como "metafísica" toda cuestión acerca de las relaciones de ese saber con la realidad tal cual, es decir, acerca de la verdad ontológica del saber científico. El escepticismo se asumió como un valor epistémico. Esta "modestia” científica y filosófica no calibró suficientemente de qué manera abría a la vez las compuertas al irracionalismo, produciendo las condiciones para que las posturas fideístas, dogmáticas y fanáticas se sintieran más legitimadas que nunca. El irracionalismo, la superstición y la mistificación ideológica se viste hoy con muchos atuendos, aun los más peregrinos y estúpidos (como los actuales creyentes en la tierra plana).

El escepticismo epistemológico no puede mantenerse. Si bien fue necesario como el signo de una modernidad antiautoritaria y antidogmática, hoy resulta insostenible e impertinente. Es necesario retornar a una racionalidad fuerte y a algo así como a una nueva metafísica. No se tratará, ciertamente, de una metafísica al modo de la antigua metafísica aristotélico-tomista ni tampoco al modo de la metafísica del racionalismo moderno - ambas deudoras de un pensamiento de la "necesidad" y del ente necesario-. Quizá haya que decir, yendo más allá de Meillassoux, que toda la filosofía desde su origen está marcada por esa forma de pensamiento, incluso que el pensamiento mismo, desde que va tomando forma en el mito, en la religión, se encuentra signado por la categoría de necesidad. Preguntar por qué y cómo existe lo que existe -la intención explicativa- conlleva ya una suposición acerca del carácter necesario de eso que existe. El punto es que el pensamiento, en su momento prerreflexivo antiguo, no se percata de que es su propia operación la que introduce el supuesto de la necesidad. El preguntar mismo está ya predeterminado por tal supuesto: es él quien se lo impone a la realidad -esta puede ser precisamente la definición de metafísica: la imposición, ingenua, de las estructuras del pensamiento a lo real-. Como sabemos, en la etapa reflexiva de la filosofía - de Descartes a Hegel- se asume que el pensamiento constituye en verdad la sustancia de lo real; la metafísica se desarrolla así en la forma de una metafisica subjetiva, que se va a prolongar hasta el siglo xx. 
Hoy debemos operar un nuevo giro reflexivo, una metarreflexión ${ }^{23}$ que nos permita volver al Ser, a lo real, pero ya sin la expectativa metafísica (tanto clásica como moderna) de localizar un orden necesario en el ser. Tal es el camino del materialismo especulativo de Meillassoux (y en gran medida, de todo el movimiento del nuevo realismo). Es posible hoy una filosofía de lo absoluto, una ontología de la realidad tal cual, ciertamente a condición de ajustar cuentas en definitiva con la idea de "ser necesario". Nada hay necesario salvo el carácter absoluto de la contingencia ("la necesidad de la contingencia", dice Meillassoux). No obstante, importa aclarar que contingencia no significa simplemente que las cosas pueden suceder de un modo u otro, esto es azar, sino, con más precisión, que no existe una razón (última, se entiende) por la que suceden de un modo o de otro. No hay una razón o causa por la que existe lo que existe; por eso, más que no haber respuesta a la pregunta fundamental: ¿̨por qué existe el ser y no la nada?, la respuesta que cabe formular es: porque el ser es contingente, por ende, existe porque existe, se basta a sí mismo (principio de irrazón) (Meillassoux, 2015, pp. 102-103); existe absolutamente, no podría no existir porque eso sería, como bien razonaba Bergson, darle más realidad a la nada que al $\operatorname{ser}^{24}$, lo cual simplemente no tiene sentido (puesto que es evidente de toda evidencia que hay ser).

La razón especulativa nos ofrece entonces una verdad absoluta acerca del Ser, aunque, ciertamente, la verdad que nos da -que todo es contingente, y absolutamente contingente- deje mucho qué desear a los espíritus que querrían certidumbres y garantías plenas. La filosofía de Meillassoux nos insta a reconocer que el ser es sin razón, que el universo todo es un gran sin sentido, una realidad absurda que no puede sustentar ninguna verdad última, ningún valor cierto. El materialismo especulativo resulta decepcionante en un primer momento. Pero solo en un primer momento; en un segundo momento, una ontología de la

23 En su deslinde crítico respecto al idealismo, tanto el clásico como el husserliano, el último MerleauPonty cuestiona el concepto de "reflexión”, como esencialmente ligado a la filosofía de la conciencia; no obstante, considera que la "filosofía de la reflexión” solo se puede superar desde dentro, por así decirlo; se trata de un movimiento en el que la conciencia vuelve sobre sí misma y busca más abajo y más allá de ella misma para, de este modo, restablecer la prioridad del Ser, de la existencia. El pensador francés llama "sobrerreflexión” a ese movimiento (Merleau-Ponty, 1966, p. 59).

24 Sobre la crítica a la confusión metafísica que da prioridad a la "nada" y a lo "posible" (pensado) sobre lo real: Bergson, 1972, pp. 94 y ss. 
contingencia nos hace ver, por el mismo principio de contingencia, que todo puede surgir, que todo puede ser, que no hay límites a las posibilidades ontológicas; que todo puede cambiar (aunque igualmente puede no cambiar), que todo puede llegar a ser mejor (e igualmente puede llegar a ser peor). Incluso, como hemos mencionado antes, que Dios puede emerger en un futuro (aunque igual, puede no emerger nunca).

Así, una filosofía abierta a la contingencia, al infinito devenir, a la posibilidad infinita, a la emergencia novedosa e imprevisible, no puede refutar la fe, al menos, como fe en la posibilidad de que emerja algo radicalmente novedoso como la justicia total, el mundo "divinológico", Dios mismo, la resurrección de los cuerpos, el "renacimiento" del ser humano, la "inmortalidad". En tanto que esta fe no hace más que expresar la asunción racional del carácter infinito del devenir, por ende, que no hay manera de quitarle ninguna de sus posibilidades, se trata de una fe racional, que es fe porque, finalmente, nada garantiza que la posibilidad divinológica se dé, aunque tampoco nada garantice lo contrario. Quizá la palabra "confianza" (que tiene la misma raíz que fe) resulte más adecuada. Hablemos así de una razón confiada y de una confianza racional. El punto es revertir al nihilismo, y revertirlo de forma definitiva.

\section{Razón especulativa y razón práctica}

Aungue la filosofía de Meillassoux implica una contestación desde el punto de vista ontológico de todo humanismo antropocéntrico, esto es, de la suplantación atea que coloca al ser humano en el lugar de Dios, la ética -asunto esencialmente humano- no desaparece de su pensamiento, por el contrario, desde su punto de vista puede ser refundada ahora en un sentido absoluto ${ }^{25}$.

Meillassoux llama "ética factual" a su propuesta para el entendimiento de la posibilidad del actuar humano. Es la opción que ofrece para afrontar el clásico problema filosófico de las relaciones entre el ser y el deber ser, entre lo real y lo

25 La tercera y última parte de Meillassoux, 1997, lleva por título "La ética divina”, por lo que podemos considerar la resolución del problema ético, es decir, la posibilidad de un actuar humano libre y conforme a la justicia y el bien, como el objetivo final de la tesis de doctorado de Meillassoux y probablemente de su proyecto filosófico como tal. 
ideal, entre la verdad y el bien, en fin, entre lo ontológico y lo ético. ¿Existe alguna relación entre ambos, alguna mediación efectiva? La respuesta a esta pregunta remite a la posibilidad efectiva del acto moral, del acto justo. ¿El Bien, la Justicia, son solamente ideales irrealizables e inalcanzables, que solo fungen como ficciones consoladoras para no afrontar "realistamente" una visión pragmática y meramente funcionalista de la vida humana? Nuestro filósofo asume -en contra del convencionalismo moral- que no es así. Que es posible acortar la distancia entre lo ontológico y lo ético y, por ende, ofrecer un fundamento realista (en un sentido amplio) de nuestro interés moral. ¿Cómo lograr ese acercamiento?

Meillassoux se detiene en un análisis histórico de las principales posturas que han buscado esa mediación entre lo real y el bien. Lo hace recurriendo, precisamente, al concepto de "símbolo" - esto es, la figura no solo teórica, sino también cultural del "mediador" (significado etimológico de símbolo: juntar, conjuntar lo separado). "El Símbolo puede ser definido entonces como lazo ontológico entre el ser y el valor" (Meillassoux, 1997, p. 303). Meillassoux localiza cuatro símbolos -cuatro concepciones del lazo entre lo real y el valor- a lo largo de la historia: el símbolo cosmológico, el símbolo naturalista, el símbolo histórico y el símbolo factual. El primero caracteriza a todo el pensamiento antiguo -grecorromano y medieval- y su idea es la suposición de una unidad suprema que ordena y organiza racionalmente todo lo existente (holismo), más allá de las vicisitudes puramente humanas; el ideal ético consiste en actuar conforme a la interpretación de ese orden cósmico. El segundo símbolo considera a la naturaleza -sus leyes, su funcionamiento- como la sustancia de todo lo existente; el ideal ético consiste en que el ser humano actúe conforme a su ser natural (el romanticismo es una variante del naturalismo). El tercer símbolo, el histórico, pertenece propiamente al mundo moderno y contemporáneo (siglos XIX-Xx) y consiste en poner al ser humano y su historia en el centro de lo real (el "humanismo"; "prometeísmo", lo llama Meillassoux); el ideal ético estriba en asumir que la razón y la voluntad humanas son capaces de transformar la realidad de forma definitiva y total de acuerdo a los dictados de nuestro conocimiento de esa realidad (Meillassoux, 1997, pp. 302-310).

Según Meillassoux, los tres símbolos, y las épocas y concepciones que representan (antigüedad, modernidad clásica y modernidad plena), han fracasado, y lo han hecho porque todos han operado bajo la categoría de necesidad. El orden 
cósmico, el orden natural o la voluntad humana son entendidos como instancias sustanciales o trascendentales que definen desde fuera o desde un nivel superior lo que existe. El simbolo factual -la propuesta del pensador francés- busca remontar esos supuestos, remontando a la vez la concepción de que los ideales morales son meras ficciones que responden simplemente a convenciones sociales o a puros intereses. En cuanto tenemos una comprensión ontológica de la contingencia como posibilidad abierta, podemos asumir que existe "una inscripción inmanente, comprensible, de los valores en el mundo" (1997, p. 302) ${ }^{26}$.

Una ética factual es aquella que parte del reconocimiento de la contingencia como cualidad esencial de lo existente, y del principio de irrazón como principio lógico-ontológico: no hay ninguna razón por la cual existe todo y por la cual existimos. Sobre la asunción de este sin sentido primario emerge la posibilidad del sentido. Al ser capaz de reconocer, mediante su razón, la contingencia y sinrazón de todo, el ser humano se confronta con su cualidad esencial y con su dignidad superior: un ser que posee la capacidad de aprehender verdades eternas, por ende, que puede concebirse a sí mismo como destinado a un Mundo diferente, no un mundo "más allá" de este, sino un nuevo Mundo dentro del mundo, un Mundo posible, el "cuarto Mundo", le llama Meillassoux ${ }^{27}$, que nada nos asegura -ni Dios, ni la lógica, ni las leyes de la naturaleza y menos las "leyes" de la historia- que pueda darse, pero tampoco que no pueda darse jamás. La fe en ese Mundo, una fe sustentada en la comprensión racional de la contingencia del ser, que descree de toda necesidad, es la primera condición para empezar a hacerlo posible desde nuestra convicción más racional y desde nuestra acción más alegremente comprometida.

26 «ne inscription immanente, compréhensible, des valeurs dans le monde. »

27 En la teoría propuesta por Meillassoux, los tres mundos previos son el Mundo de la materia, el Mundo de la vida y el Mundo del pensamiento. Cada uno de estos mundos es autónomo (por eso Meillassoux los escribe con mayúscula), ha aparecido como producto de un "fíat", de una "emergencia" (surgimiento sin causa). Ahora bien, solo el tercer mundo "conoce" y anticipa la posibilidad de un cuarto mundo, pues el ser humano revela para sí mismo que el sentido de su existencia no se puede reducir a lo dado (los tres mundos en los que participamos como seres físico-biológicoculturales) sino que debe apuntar a un nuevo Mundo, el cuarto, el mundo inmortal de la justicia universal, que debería aparecer, no obstante, como parte de este mismo mundo (Meillassoux, 1997, pp. 290-293). 
A fin de evitar cualquier forma de determinismo - un "determinismo" de la contingencia-, y de conjuntar la idea de contingencia con la del principio ético de universalidad (principio de justicia) Meillassoux define dos momentos de la ética factual. Un primer momento consiste en la esperanza en la inmortalidad, en el renacimiento del ser humano (de la resurrección de los cuerpos) en el cuarto Mundo, el mundo divinológico de la justicia. El segundo momento consiste en la capacidad del ser humano para contribuir activamente al advenimiento de ese cuarto Mundo. Meillassoux rechaza la posición "fatalista", de quien simplemente se sentaría a esperar ese advenimiento. Nunca va a llegar así. El error del fatalista radica en que hace del renacimiento, de la inmortalidad, el objeto de un puro deseo individual arbitrario - lo toma como un fin en sí mismo y no como un medio para el fin superior y universal de la justicia plena-. Por el contrario, el advenimiento de lo universal requiere "que él sea deseado en acto" (Meillassoux, 1997, p. 335). Esperarlo pasivamente es no esperarlo, pues esto implica hacer de lo universal un objeto extraño a nosotros mismos, es reificarlo y, por ende, volverlo imposible. Querer la inmortalidad sin desear el advenimiento de la justicia universal es invocar una mera repetición de lo mismo, un eterno retorno de lo que es, como es, sin cambio ni novedad. Más que vida inmortal lo que tendríamos sería una muerte eterna. Por el contrario, la inmortalidad solo tiene sentido y razón para el fin de la justicia universal. Deseo de inmortalidad y deseo de justicia se determinan mutuamente como el deseo propiamente humano.

Cada vez que obro con la mira en la justicia, renuevo así la expectativa que da sentido a la posibilidad del surgimiento de otro Mundo, que no sería simplemente repetición de un Mundo de vida o de pensamiento, sino que constituiría el último Mundo -el Mundo de justicia (Meillassoux, 1997, p. 237)-.

\section{Conclusión: refutación del nihilista}

¿Tiene sentido esta fe Racional en un Mundo divinológico, de justicia y bondad plenas? ¿Cuál es el valor y la plausibilidad de la propuesta de irreligión filosófica de Meillassoux? En las partes finales de su tesis de doctorado, el filósofo francés insiste en su crítica a la religión y al ateísmo y en la necesidad de encontrar una alternativa distinta, que no sería otra que la propia filosofía. La llama lo "divino filosófico", la "ética divina”. Es la respuesta, la máxima respuesta 
racional posible, al compromiso ineludible del ser humano con la exigencia de justicia plena. En esta exigencia se funda el deseo de inmortalidad (y no al revés, como suponía Kant), la inmortalidad como tal que, según Meillassoux, no es un concepto religioso (como es el de "eternidad"), sino básicamente filosófico, el concepto propio de la "irreligión" filosófica, de alguna manera presente siempre en la historia de la filosofía.

La inmortalidad filosófica se opone en efecto a la trascendencia religiosa de la manera siguiente: el sacerdote promete, por la trascendencia, otra vida, el filósofo, por la inmortalidad, promete todavía esta vida. Pues la filosofía, fiel a ella misma en su lanzamiento platónico, es la afirmación de una perpetuación posible e infinitamente deseable de esta vida, con exclusión de cualquier otra. De la metempsicosis platónica al eterno retorno nietzscheano, pasando por la eternidad espinosista o la inmortalidad kantiana. La filosofía intenta obstinadamente la elaboración de un concepto consistente de la inmortalidad, por el cual esta vida se afirma como la única, y como la única deseable (1997, pp. 359-360 $)^{28}$.

Pero hay todavía, además del religioso y el ateo, un tercer oponente, el más difícil y, a la vez, el más actual: el nihilista. Frente a él, la ontología especulativa despliega su última batalla. A diferencia del religioso, que considera que el mundo de la justicia es deseable pero solo es realizable en el otro mundo, y del ateo, para quien el mundo de justicia es deseable pero no es realizable en este mundo ni en ningún otro, el nihilista cree que el mundo de justicia puede ser realizable (en cierto modo el nihilista admite el principio de contingencia) pero no es necesariamente deseable. ¿Qué se le puede responder a esta postura extrema de desánimo y descreimiento?

28 « L'immortalité philosophique soppose en effet à la transcendance religieuse de la façon suivante: le prétre promet, par la transcendance une autre vie, la philosophie, para la immortalité, promet encore cette vie. Car la philosophie, fidèle à elle-même dans son lancement platonicien, est l'affirmation d'une perpetuation possible et infiniment désirable de cette vie, à la exclusion de toute autre. De la métempsycose platonicienne à l'Éternel Retour nietzschéen, en passant par l'éternité spinoziste ou l'immortalité kantienne, la philosophie tente obstinément l'élaboration d'un concept consistant de l'immportalitépar quoi cette vie s'affirme comme la seule, et comme la seule désirable. » 
El nihilista pasa por la experiencia de la desesperación ante el mundo existente y la imposibilidad de la justicia: asume que la realidad es el reino irredimible del mal y del fracaso. Pero, se pregunta, ¿qué pasaría si la inmortalidad, el mundo divinológico, se alcanzara? Su respuesta es que esa realización no es deseable porque entonces ya no habría "deseo", se acabaría la motivación para actuar y vivir, que es lo verdaderamente importante. En un segundo momento, el nihilista señala igualmente que el deseo desinteresado, individual, se exterminaría si se alcanzara el mundo de la justicia universal, que sería un mundo de emparejamiento y abstracción. Para el nihilista, la acción y el deseo solo tienen valor si el individuo no alcanza sus propósitos, si permanentemente fracasa, pues si los alcanzara entonces dejaría de actuar y de desear ${ }^{29}$. Este es un argumento claramente irracional, pero es la irracionalidad, el ominoso sin sentido de la vida humana (el mito de Sísifo), lo que el nihilista finalmente "valora".

Meillassoux responde a la postura del nihilista con dos aclaraciones: (1) la inmortalidad no es exterior a la vida presente, y no es lo mismo que la "sempiternidad” (la representación religiosa de la eternidad como un no-tiempo); (2) lo universal no es exterior al deseo humano; el deseo de justicia se afirma en el gesto individual de afirmación de la vida, en la conciencia de la contingencia y la finitud (1997, pp. 366 y ss). El nihilismo es, al fin, la expresión suprema de la enajenación humana, que considera cualquier posibilidad de "redención", "salvación" o "justicia" como esencialmente extraña al mundo, como "imposible" para el ser humano. El nihilista radicaliza el sentimiento religioso y ateo de la indignidad del ser humano, de su condena a la miseria moral, a la impotencia y al sinsentido. Toda posibilidad está excluida de principio.

La importancia de la refutación del nihilista estriba en que, finalmente, su postura solo recoge y exhibe el núcleo de las posturas religiosa y atea. La esencia de la religión y el ateísmo es el nihilismo, la negación de los poderes de la vida, y todavía más, la negación absoluta del poder extremo de la vida que es la inmortalidad, la vida inmortal. La asunción de la ontología factual de la inmortalidad como potencia última de la vida cuestiona profundamente las visiones religiosa y atea, desnudando el carácter nihilista de ambas, en cuanto las dos coinciden

29 Como en otros casos, Meillassoux (1997, pp. 349-362) hace una tipología de la postura nihilista y no refiere a alguna figura filosófica o cultural en particular. 
en su aceptación de un principio de necesidad absoluto que rige lo existente, ya como mandato divino o ya como leyes naturales. A la vez, la ontología factual desnuda el carácter religioso y metafísico del nihilismo en cuanto este asume, más que nadie, la imposibilidad de superar la condena teológica o la condena naturalista a vivir en un mundo sin valor ni sentido. Por el contrario, al radicalizar ontológicamente el sinsentido del mundo, la contingencia de todo lo que existe, la filosofía especulativa de Meillassoux también puede radicalizar la propia contingencia del sinsentido al extremo, en su último nivel, en la última apuesta, donde hace emerger ahí la posibilidad del sentido. Es la inmanencia radical, "la inmanencia del otro-mundo", la clave de la apuesta filosófica de Meillassoux. Otro mundo es posible, desde aquí, desde ahora.

Encontrar una salida todavía racional, filosófica, al mundo nihilista y desencantado de nuestra época, recuperando la esperanza en la justicia y el bien mediante una ontología liberada de todo determinismo, tal es el proyecto de la filosofía irreligiosa de Meillassoux. Más allá de la aceptabilidad general, social y humana, de tal proyecto, nos queda la inquietud teórica que sus propuestas y argumentos nos provocan y que nos hacen recuperar la esperanza, al menos, en el poder del pensamiento, en la capacidad de la filosofía para renovarse, para abrir nuevos horizontes y reabrir horizontes olvidados, para dar todavía clarividencia, sentido y tarea a nuestras vidas.

\section{Referencias}

Bergson, H. (1972). Elpensamiento y lo moviente. (Trad. M. H. Alberti). Buenos Aires: La Pléyade.

Bloch, E. (1983). El ateísmo en el cristianismo. (Trad. J. A. Gimbernat). Madrid: Taurus.

Bloch, E. (2004-2007). El principio esperanza (Vols. 1-3). (Trad. F. González Vicén). Madrid: Trotta.

Brassier, R. (2017). Nibil desencadenado. (Ilustración y extinción). (Trad. B. García Bercero). Segovia: Materia Oscura.

Bryant, L., Srnicek, N., \& Harman, G. (Eds.). (2010). The Speculative Turn: Continental Materialism and Realism. Melbourne: Re.Press. 
Caligari, G., \& Starosta, G. (2015). La crítica marxiana de la dialéctica hegeliana. De la reproducción ideal de un proceso ideal a la reproducción ideal de un proceso real. Praxis Filosófica, 41, 81-112. doi: https://doi.org/10.25100/ pfilosofica.v0i41.3182

Deleuze, G. (2012). Diferencia y repetición. (Trad. S. Delpi \& H. Beccacece). Buenos Aires: Amorrortu.

Derrida J., \& Vattimo, G. (1997). La religión. Seminario de Capri. (Trad. C. de Peretti et al.). Buenos Aires: La Flor.

Dussel, E. (1993). Las metáforas teológicas de Marx. Pamplona: Verbo Divino.

Ferraris, M. (2013). Manifiesto del nuevo realismo. (Trad. J. Blanco et al.). Madrid: Biblioteca Nueva.

Feuerbach, L. (1941). La esencia del cristianismo. (Trad. F. Huber). Buenos Aires: Claridad.

Frey, H. (2009). ¿Qué Dios ha muerto? Nietzsche: el nihilista antinihilista. Revista Mexicana de Sociología, 71(4), 715-736.

Gabriel, M. (2017). Sentido y existencia. Una ontología realista. (Trad. R. Gabás). Barcelona: Herder.

Gilson, E. (1965). La filosofía en la Edad Media. (Trad. A. Pacios \& S. Caballero). Madrid: Gredos.

Gratton, P., \& Ennis, P. J. (2015). The Meillassoux Dictionary. Edimburgh: Edimburgh University Press.

Harman, G. (2011). Quentin Meillassoux. Philosophy in the Making. Edinburgh: Edinburgh University Press.

Harman, G. (2015). Hacia el realismo especulativo. (Trad. C. Iglesias). Buenos Aires: Caja Negra.

Harman, G. (2018). Speculative Realism. An Introduction. Cambridge: Polity Press.

Hegel, G. W. F. (1981). El concepto de religión. (Trad. A. Guinzo). Ciudad de México: Fondo de Cultura Económica.

Hegel, G. W. F. (2010). Fenomenología del espiritu. (Trad. J. Chamorro). Madrid: Gredos.

Hume, D. (1994). Diálogos sobre la religión natural. (Trad. Carmen GarcíaTrevijano). Madrid: Tecnos.

Kant, E. (2010). Crítica de la razón pura. (Trad. P. Ribas). Madrid: Gredos. 
Marx, K. (1999). El capital. Crítica de la economía politica (Vol. 1). Ciudad de México: Siglo XXI.

Meillassoux, Q. (1997). Linexistence divine (Tesis doctoral inédita). Universidad de París, París.

Meillassoux, Q. (2006). Après la finitude. Essai sur la nécessité de la contingence. Paris: Seuil.

Meillassoux, Q. (2007a). Matérialisme et surgissement ex nihilo. MIR: Revue d'anticipation, (1), 52-69.

Meillassoux, Q. (2007b). Presentation. En: R. Mackay, Collapse. Philosophical Research and Development III (pp. 408-449). Falmouth: Urbanomic.

Meillassoux, Q. (2009). L'immanence d'outre-Monde. Ethica, 2, 39-71.

Meillassoux, Q. (2011). Le Nombre et la sirène. Un déchiffrage du Coup de dés de Mallarmé. París: Fayard.

Meillassoux, Q. (2015). Después de la finitud. Ensayo sobre la necesidad de la contingencia. (Trad. M. Martínez). Buenos Aires: Caja Negra.

Meillassoux, Q. (2016). Dios por venir, duelo por venir. En: M. T. Ramírez (Ed.), El nuevo realismo. La filosofía del siglo XXI (pp. 101-111). Ciudad de México: Siglo XXI.

Meillassoux, Q. (2017). Dueil à venir, Dieu à venir. París: Ismael (reedición del artículo publicado en Critique, 704-705, “Dieu”, janvier-février 2006, París: Minuit, pp. 105-115. Disponible en https://editions-ismael.com).

Meillassoux, Q. (2018a). Duelo por venir, Dios por venir. En: Hipercaos (pp. 5166). ( $\operatorname{Trad}$ J. Fernández). Salamanca: Holobionte.

Meillassoux, Q. (2018b). Potencialidad y virtualidad. En: Hipercaos (pp. 93121). (Trad J. Fernández). Salamanca: Holobionte.

Merleau-Ponty, M. (1966). Lo visible y lo invisible. (Trad. J. Escudé). Barcelona: Seix Barral.

Nietzsche, F. (1974). El anticristo. Maldición sobre el cristianismo. (Trad. A. Sánchez Pascual). Madrid: Alianza.

Nietzsche, F. (2010). Más allá del bien y del mal. (Trad. C. Vegara). Madrid: Gredos.

Pegueroles, J. (1972). El pensamiento filosófico de San Agustin. Barcelona: Labor. Ramírez, M. T. (2016). Devenir inmortal. La crítica de Quentin Meillassoux a la filosofía de la inmanencia de Gilles Deleuze. En: M. T. Ramírez (Ed.), 
El nuevo realismo. La filosofía del siglo XXI (pp. 193-2010). Ciudad de México: Siglo XXI.

Roggero, J. L. (2017). La "dimensión religiosa” de la fenomenología de la donación de J.-L. Marion. Éndoxa: Series Filosóficas, 40, 335-354. doi: https:// doi.org/10.5944/endoxa.40.2017.17001 